\title{
Suction effects on the tensile strength and unconfined compression of unsaturated soils
}

\author{
Pedro Roque ${ }^{1 *}$,Mariana Motta $^{2}$, and Tácio de Campos ${ }^{1}$ \\ ${ }^{1}$ PUC-Rio, RJ, Brazil \\ ${ }^{2}$ UNISAL, SP, Brazil
}

\begin{abstract}
The soil-water characteristic curve is an important relation of unsaturated soils, that expresses the variation of the amount of water retained in the soil as a function of its suction. In these soils, drying or wetting can have a great influence on their resistance parameters. This work presents and discusses the effects of increased suction on the tensile strength and unconfined compression of unsaturated soils. Suction was evaluated using the filter paper and the dew point technique, while the resistance parameters were obtained through the "Brazilian Test" and uniaxial compression. Three different soils from Rio de Janeiro were studied: two young residual soils, in which the influence of the soil structure was also verified through tests on undisturbed and reconstituted samples, and a colluvial soil. The results allowed to conclude that the increase of suction, in a first moment, generates an increase in the resistance parameters of these soils. With the continuation of the drying process, the mechanical behaviour of the soils varied, being able to maintain the resistance or showing a drop related to high suction values.
\end{abstract}

\section{Introduction}

Unsaturated soils, when exposed to alternation between dry and rainy periods, have wetting and drying cycles. This variation in their saturation generates major changes in behavior, especially in their resistance parameters.

In this context, this work aims to conduct a research on the effect of suction and the structure of unsaturated soils in such parameters, through tests of diametrical compression and unconfined compression in undisturbed and reconstituted samples with different suction values imposed arbitrarily. Thus, the following specific objectives were established:

- Check and analyze how suction affects the tensile strength and unconfined compression of two residual soils and a colluvium from Rio de Janeiro, in addition to the elastic modulus obtained from the stress vs. strain curves. - Evaluate and compare two techniques for measuring soil suction, namely: filter paper and the dew point technique. - Evaluate the influence of the structure of young residual soils by comparing the curves tensile strength vs. suction and unconfined compression resistance vs. suction, with undisturbed and reconstituted samples.

The proposed study is necessary because in Rio de Janeiro the physical environment consists of residual soils. Due to their origin, location and climatic peculiarities, such soils are typically unsaturated.

As this type of material prevails in southern countries, and most of Soil Mechanics was developed in the northern countries, considering saturated sediments, there is little information about the engineering behavior of unsaturated residual soils. It is not surprising, therefore, the difficulty of understanding and explaining, based on scientifically based arguments, the occurrence of slope slides, often catastrophic, involving these types of soils, in association or not with colluvium, also unsaturated.

Therefore, this study will contribute to understanding the behavior of these soils that were until recently disregarded in engineering designs.

\section{Studied soils}

To meet the proposed objectives, soils from three different locations in Rio de Janeiro State were selected to carry out the tests.

The first material studied was a young leukogneiss residual soil from the Biological Reserve Tinguá, in Nova Iguaçu. This location was chosen due to the creep movements that occurred in the gas pipelines from Transpetro in November 2009.

The second soil is another young residual soil originated from ortogneiss and granitoid weathering process and was taken from a slope in Condomínio do Lago, in Nova Friburgo. This choice is related to the natural disaster that occurred in January 2011 in the mountainous region of the State of Rio de Janeiro.

The third study site was PUC-Rio's Experimental Field II, located on a hillside inside the university, where colluvial gneiss soils predominate. This soil was chosen because it has a large amount of information about it in several academic works (Brito 1981 [1]; Soares 2005 [2]). In addition, as it is within the University, it provided a simpler sampling.

For these three soils studied, undisturbed material was collected through block sampling, as shown in Fig. 1. The block of soil was transported to the laboratory where it

*orresponding author: pedro_roque_93@yahoo.com.br 
was stored in a chamber with controlled temperature and humidity.

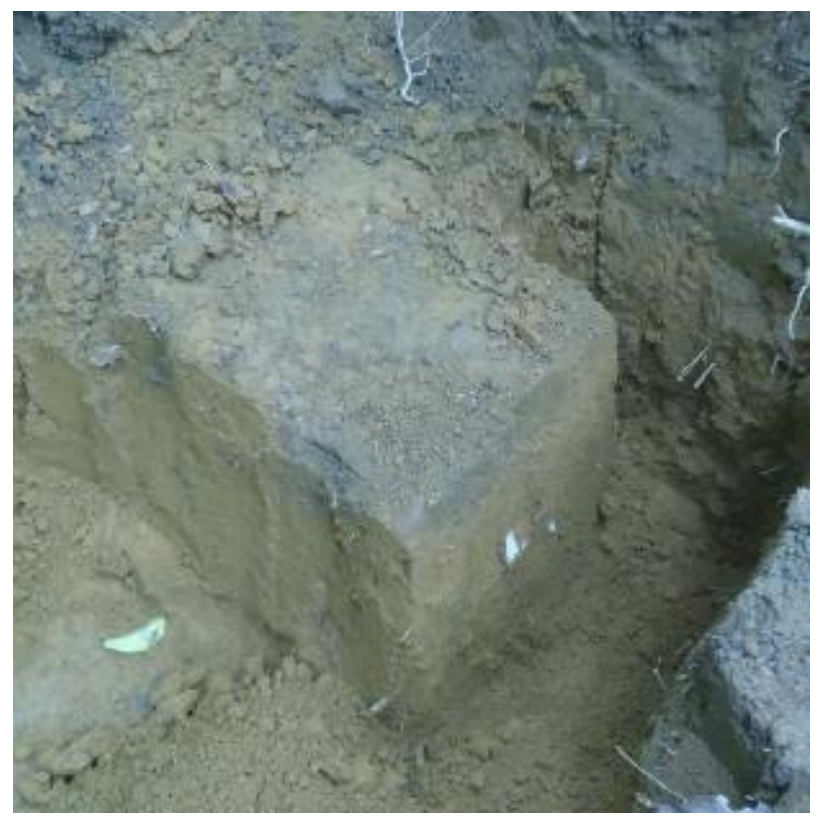

Fig. 1. Block sampling of PUC's colluvium.

In addition to the soil block, disturbed samples were collected to perform physical characterization tests in laboratory. The tests were carried out to obtain the following soil properties:

- Grain size distribution curve,

- Relative grain density $\left(\mathrm{G}_{\mathrm{S}}\right)$,

- Atterberg's Limits ( $\left.\mathrm{w}_{\mathrm{L}}, \mathrm{w}_{\mathrm{P}}\right)$ and Plasticity Index $\left(\mathrm{I}_{\mathrm{P}}\right)$, and - Activity of clay (Ia).

The results are presented in Table 1. Due to the low clay content and the presence of micas, it was not possible to determine the Atterberg's Limits and Activity of the two residual soils. It was also possible to classify the materials according to the Unified Soil Classification System (USCS).

Table 1. Physical properties of the three soils studied and their Unified Soil Classification.

\begin{tabular}{c|c|c|c|c|c|c}
\hline & Gs & $\begin{array}{c}\text { WL } \\
(\boldsymbol{\%})\end{array}$ & $\begin{array}{c}\text { WP } \\
(\boldsymbol{\%})\end{array}$ & $\begin{array}{c}\text { IP } \\
(\boldsymbol{\%})\end{array}$ & Ia & USCS \\
\hline Tinguá & 2.766 & - & - & - & - & SM \\
Friburgo & 2.667 & - & - & - & - & SM \\
PUC & 2.739 & 57 & 29 & 28 & 0.5 & $\mathrm{CH}$ \\
\hline
\end{tabular}

\section{Methodology}

For each test, undisturbed and reconstituted samples were molded. The undisturbed samples were obtained directly from the soil block. The reconstituted samples were obtained in the laboratory from disturbed soil, maintaining the void ratio and gravimetric moisture content of the undisturbed samples, but suppressing the natural structure of the soil originated from its formation process. For this, the amount of soil needed to fill the known volume of the ring or cylinder was calculated. The specimens were then molded by manual compaction in layers of similar thickness as shown in Fig. 2 to obtain a specimen of the Tinguá young residual soil. After the compaction of each layer, the soil was scarified to increase adherence with the overlying layer.

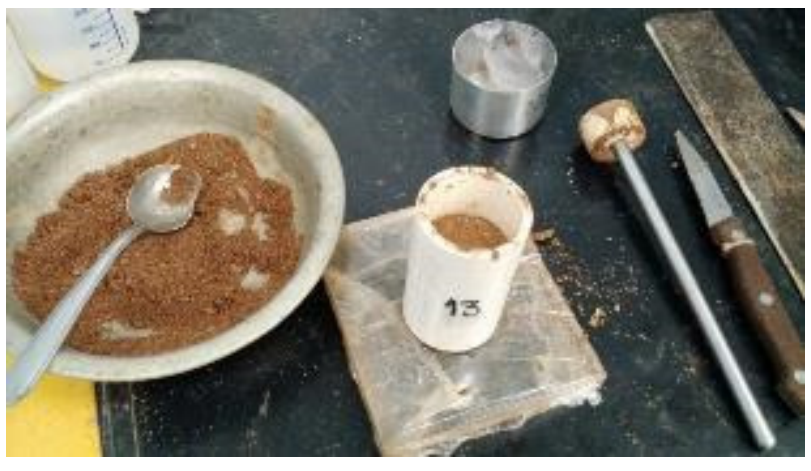

Fig. 2. Reconstituted sample compaction.

\subsection{Soil-water characteristic curve}

The main methodology used to obtain the soil-water characteristic curve of the soils studied in this work was the filter paper technique (Marinho 1994 [3]). For the determination of high suction values, the WP4C Dewpoint Potentiometer was also used. Since the first technique measures matric suction and the second measures total suction, the hybrid soil-water characteristic curve was obtained.

The samples were fully saturated by capillarity and then air-dried until reaching the previously arbitrated mass corresponding to the desired degree of saturation. At the end of this process, the samples were equalized for three days and placed in contact with Whatman Grade 42 filter paper, at the top and bottom. Each ring was wrapped in PVC film and aluminum foil. Then, they were stored in a polystyrene box to maximize thermal insulation.

To provide equalization of the matric suction, the samples remained in the box for a period of 7 to 10 days. After this interval, they were opened, and the filter papers were placed directly on a high precision scale. The mass of the paper was observed for each previously determined time value $(10,20,30,40,50$ and 60 seconds) and, by exponential correlation, the wet filter paper mass was obtained in time equal to zero. This procedure was again performed to obtain the dry filter paper mass after drying in an oven at $110^{\circ} \mathrm{C}$ for a period of two hours.

The moisture content of the filter paper $\left(w_{p}\right)$ is calculated from the dry mass and the wet mass. The matric suction value $\left(u_{s}\right)$ of each sample is determined based on the moisture content of the filter paper according to the calibration equation proposed by Chandler et al. (1992) [4], as seen on equation (1).

$$
\begin{aligned}
& \text { if } w_{p}>47 \% \text {, then } \mathrm{u}_{\mathrm{s}}=10^{[6.05-2.48 \log (w p)]} \\
& \text { if } w_{p}<47 \% \text {, then } \mathrm{u}_{\mathrm{s}}=10^{[4.84-0.0622(w p)]}
\end{aligned}
$$

In addition to the filter paper method, higher values of total suction were also obtained using the WP4C Dewpoint Potentiometer, from Decagon Devices.

With a small amount of disturbed soil, the WP4C is capable, after a few minutes of equalization, to provide 
the value of the total suction of the soil. After the suction determination with the filter paper technique and the unconfined compression and diametrical compression tests, a portion of the material was inserted in the equipment.

\subsection{Tensile strength}

The tensile strength of the studied soils was obtained through the diametrical compression test, known as the "Brazilian Test". In this test, the samples have the same dimensions as those used in the filter paper method - 4.7 $\mathrm{cm}$ in diameter $(D)$ and $2.1 \mathrm{~cm}$ height $(H)$ - so they were used after equalizing and weighing the filter paper to be tested.

A triaxial press was adapted to compress the samples in the direction of their diameter (Fig. 3). The loading applied to the specimens, controlled by the "Clip Studio" software, took place along two parallel and opposite rigid surfaces, with a displacement rate of $0.3 \mathrm{~mm} / \mathrm{min}$.

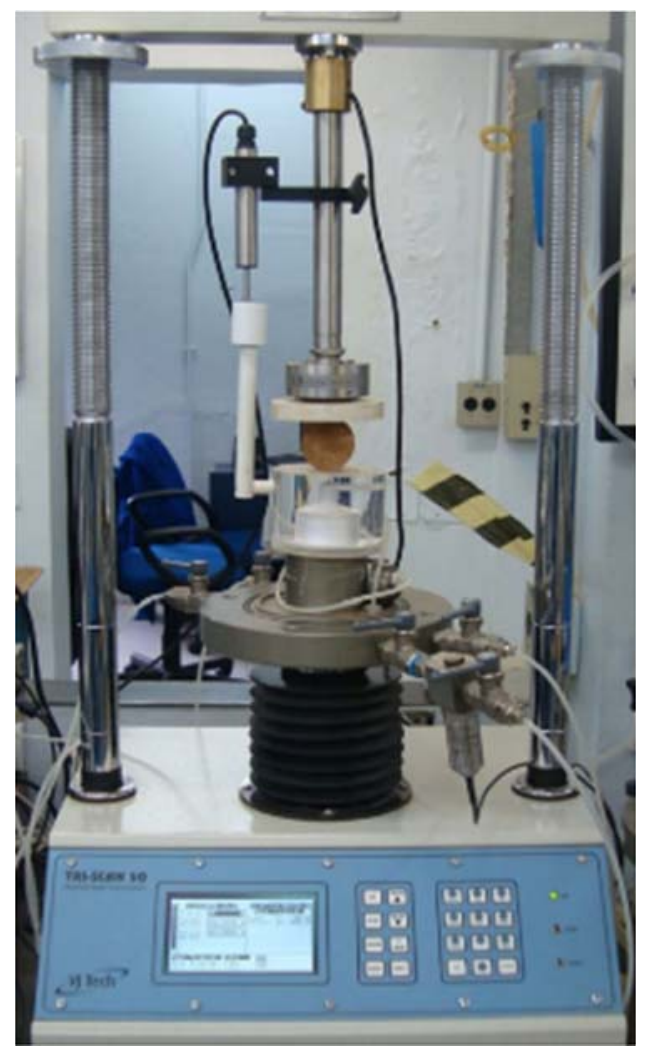

Fig. 3. Adapted triaxial press to diametrical compression.

Using the rupture load $(P)$ recorded by the force transducer and the dimensions of the tested sample, it was possible to obtain the tensile strength value $\left(\sigma_{t}\right)$ through equation (2).

$$
\sigma_{t}=2 P / \pi D H
$$

\subsection{Unconfined compression}

The unconfined compression test, also known as uniaxial compression, is the fastest and simplest method for obtaining the shear strength of a given soil. Unconfined compression strength is given by the maximum load in the stress vs. strain curve.

Undisturbed and reconstituted samples were used, molded in PVC cylinders of $3.8 \mathrm{~cm}$ diameter and $7.6 \mathrm{~cm}$ height, with different moisture contents. The sample preparation followed the same procedure described in the previous items.

The loading of the samples was carried out in an adapted triaxial press, but with the imposed displacement rate of $0.4 \mathrm{~mm} / \mathrm{min}$.

It is important to note that both the unconfined compression tests and the tensile strength tests are quick tests carried out in undrained conditions at constant water content. Suction was measured immediately before the start of the test, but it most likely changes during the procedure and no measurements were made.

\section{Results and discussion}

\subsection{Tinguá young residual soil}

\subsubsection{Soil-water characteristic curve}

The results of the Tinguá young residual soil in terms of volumetric moisture content for undisturbed and reconstituted samples are presented in Fig. 4.

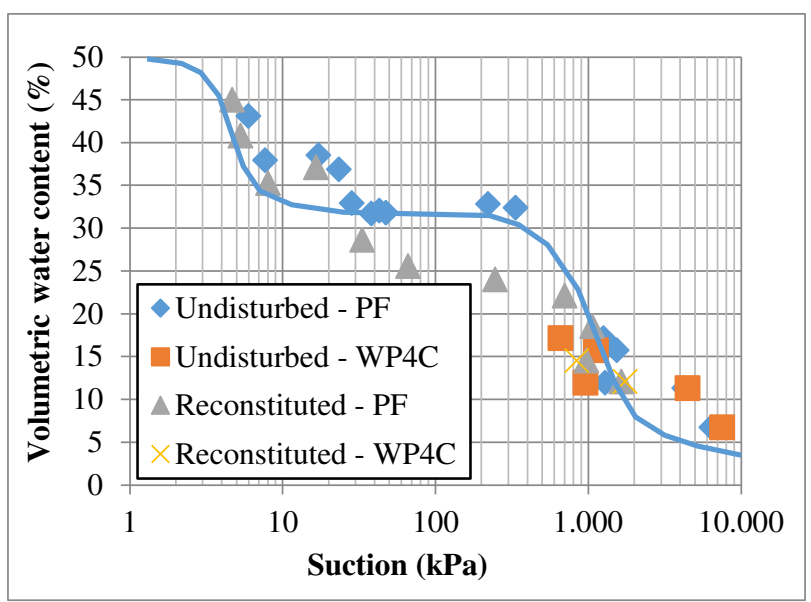

Fig. 4. Tinguá young residual soil. Soil-water characteristic curve.

The soil-water characteristic curve of this soil showed a bimodal behavior. The curves of the undisturbed and reconstituted samples were similar, with the first air-entry value almost coincident, at $3 \mathrm{kPa}$. However, from then on, the soil-water characteristic curve of the reconstituted samples shifted down and to the left. The value of residual suction and the second air-entry value observed were lower.

Graphically, it was observed that the value of the first residual suction of the soil-water characteristic curve of undisturbed samples was approximately $16 \mathrm{kPa}$. Continuing the drying process, the soil showed a second air-entry with suction values of $420 \mathrm{kPa}$, while the residual suction was $2 \mathrm{MPa}$. 
As for the reconstituted samples, the soil-water characteristic curve showed a slight displacement down and to the left, generating lower values of the first residual suction (around $10 \mathrm{kPa})$, second air-entry value $(200 \mathrm{kPa})$ and second residual suction (1.2 $\mathrm{MPa})$.

\subsubsection{Tensile strength}

The soil structure had an important influence on tensile strength, with different behavior in undisturbed and reconstituted samples. Fig. 5 presents the experimental points of the tensile strength tests as a function of initial soil suction for undisturbed and reconstituted samples.

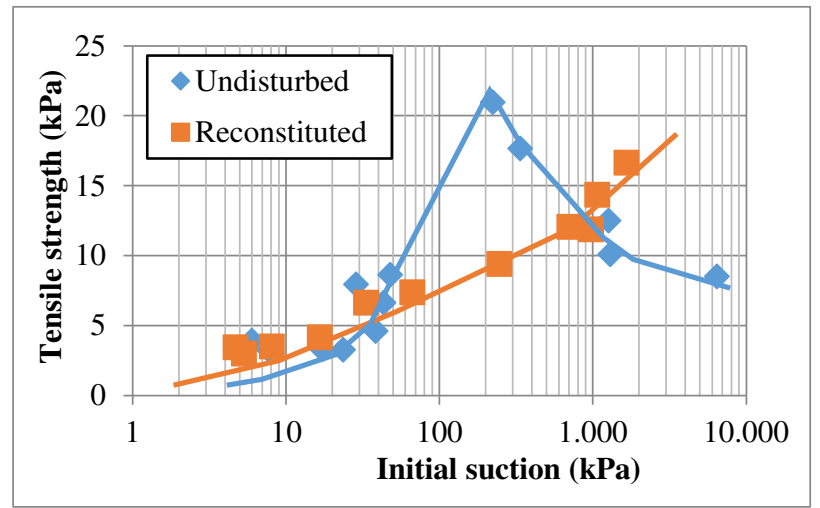

Fig. 5. Tinguá young residual soil. Initial suction vs. tensile strength.

On the undisturbed samples, the suction increase generated a resistance gain until reaching a maximum of $21 \mathrm{kPa}$, with a matric suction of approximately $200 \mathrm{kPa}$. Thereafter, the drying of the material and the consequent increase in suction generated a loss of resistance, with minimum values of $5 \mathrm{kPa}$.

Meanwhile, the tensile strength in the reconstituted samples gradually increased, reaching maximum values above $21 \mathrm{kPa}$, with a recorded suction of $15 \mathrm{MPa}$. Motta (2016) [5] proposed that the alignment of the micas would justify this difference between both materials, since in the undisturbed samples these minerals would be arranged in the direction of the failure.

\subsubsection{Unconfined compression strength}

The results of the unconfined compression strength as a function of initial suction can be seen in Fig. 6. The uniaxial compression tests showed that the soil structure did not influence the way the suction interferes in the resistance, with both groups of samples behaving similarly.

As in the reconstituted samples tested to diametrical compression, the drying process generated an increase in soil resistance, ranging from values of about $30 \mathrm{kPa}$ for suction below $10 \mathrm{kPa}$ to values above $140 \mathrm{kPa}$ for soil suction of $2.8 \mathrm{MPa}$.

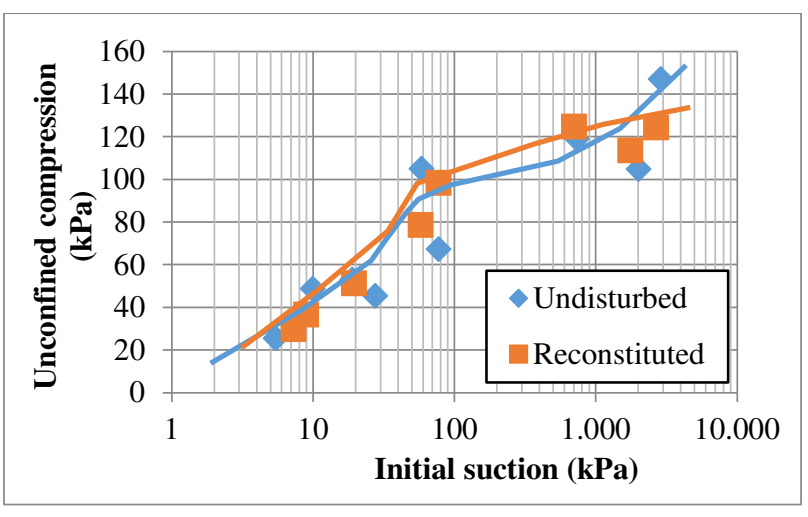

Fig. 6. Tinguá young residual soil. Initial suction vs. unconfined compression strength.

Fig. 7 shows the failure surfaces of some samples.

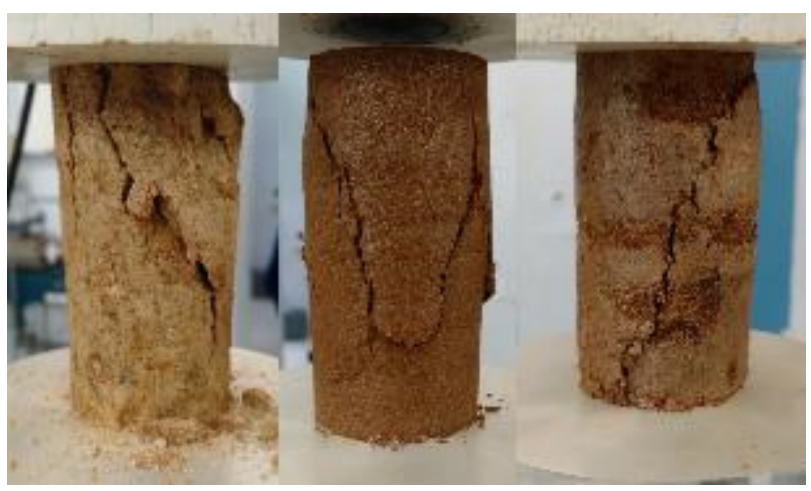

Fig. 7. Tinguá young residual soil. Failure surfaces.

Fig. 8 and 9 present the stress vs. axial strain curves for undisturbed and reconstituted samples, respectively. The behavior of the elastic modulus was similar for both undisturbed and reconstituted samples, with its increase as the soil reached higher initial suction values.

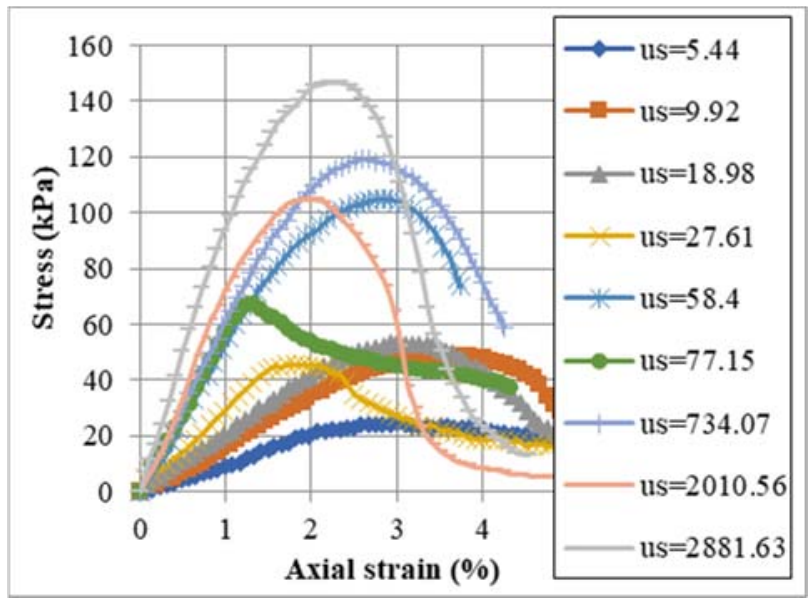

Fig. 8. Tinguá young residual soil undisturbed samples. Stress vs. axial strain. Initial suction $\left(\mathrm{u}_{\mathrm{s}}\right)$ values in $\mathrm{kPa}$. 


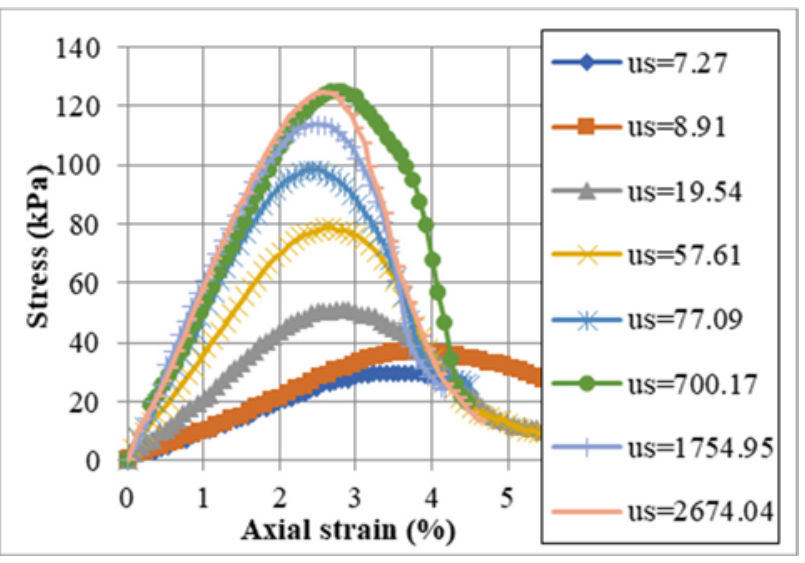

Fig. 9. Tinguá young residual soil reconstituted samples. Stress vs. axial strain. Initial suction $\left(\mathrm{u}_{\mathrm{s}}\right)$ values in $\mathrm{kPa}$.

\subsection{Friburgo young residual soil}

\subsubsection{Soil-water characteristic curve}

Fig. 10 presents the results of suction, obtained through the filter paper method and the WP4C potentiometer, from Friburgo young residual soil in terms of volumetric moisture content for undisturbed and reconstituted samples. Unlike the Tinguá soil, the soil-water characteristic curve of this soil showed unimodal behavior, with only one air-entry value and one residual moisture content. The undisturbed and the reconstituted samples showed significantly similar results, demonstrating that the structure did not influence the suction of this soil.

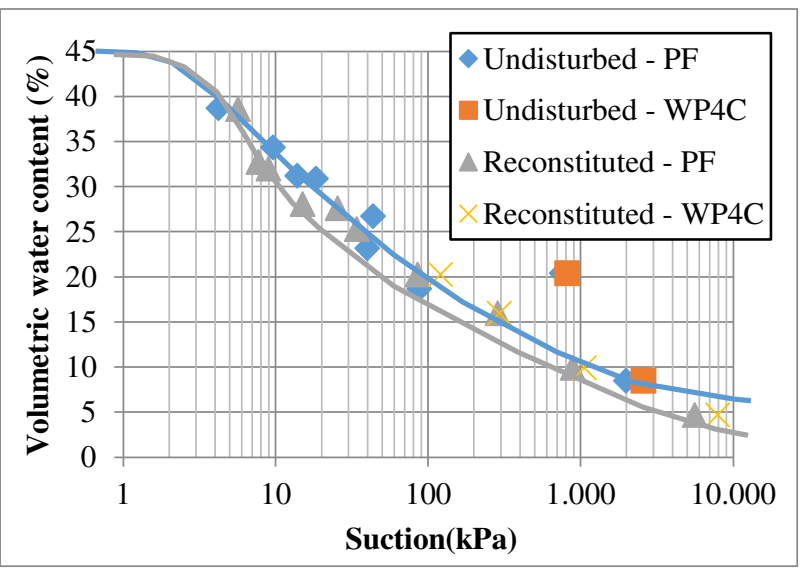

Fig. 10. Friburgo young residual soil. Soil-water characteristic curve.

Graphically, it was possible to obtain the matric suction values for the air-entry and the residual moisture content of the soil-water characteristic curve. For undisturbed samples, the air-entry value was $4 \mathrm{kPa}$, while the residual moisture was at $350 \mathrm{kPa}$. For reconstituted samples, the first value was $2.8 \mathrm{kPa}$ and the second $220 \mathrm{kPa}$. These values were evaluated and presented by Motta (2016) [5].

\subsubsection{Tensile strength}

The experimental points obtained by the Brazilian Test with undisturbed and reconstituted samples with different arbitrated suction values are presented in Fig. 11.

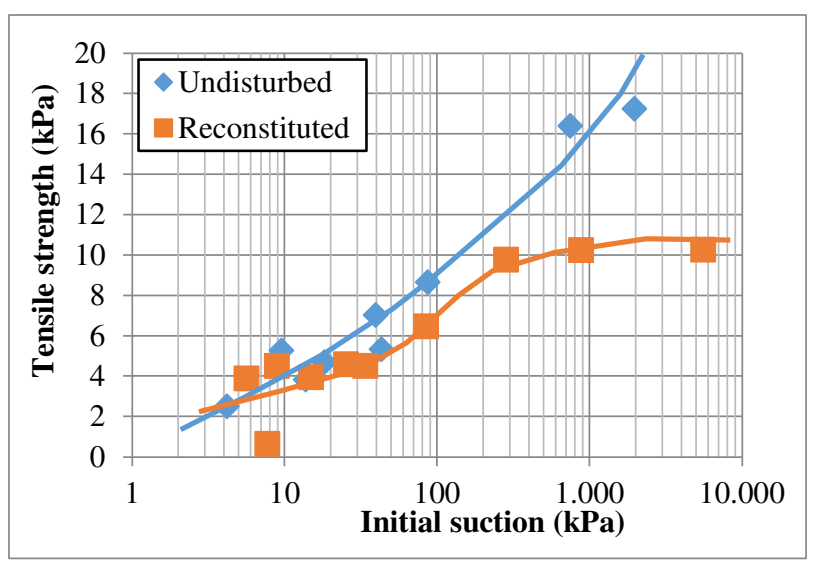

Fig. 11. Friburgo young residual soil. Initial suction vs. tensile strength.

The results of the diametrical compression tests of this soil showed that both undisturbed and reconstituted samples showed a gradual gain in tensile strength with the increase of suction up to the residual moisture value (200 $\mathrm{kPa})$.

The resistance behavior from this value was similar for the undisturbed and reconstituted samples. For the first group, however, there was a greater increase in this parameter, reaching a maximum tensile strength of $17 \mathrm{kPa}$, achieved with suction values in the order of $2 \mathrm{MPa}$. For the second group, the tensile strength of the soil remained relatively constant, not exceeding values above $10 \mathrm{kPa}$ for suction values equal to or greater than $280 \mathrm{kPa}$. This difference can be explained by the presence of the rock structure that originated this residual soil in undisturbed samples.

\subsubsection{Unconfined compression strength}

The results of the unconfined compression strength as a function of initial suction can be seen in Fig. 12.

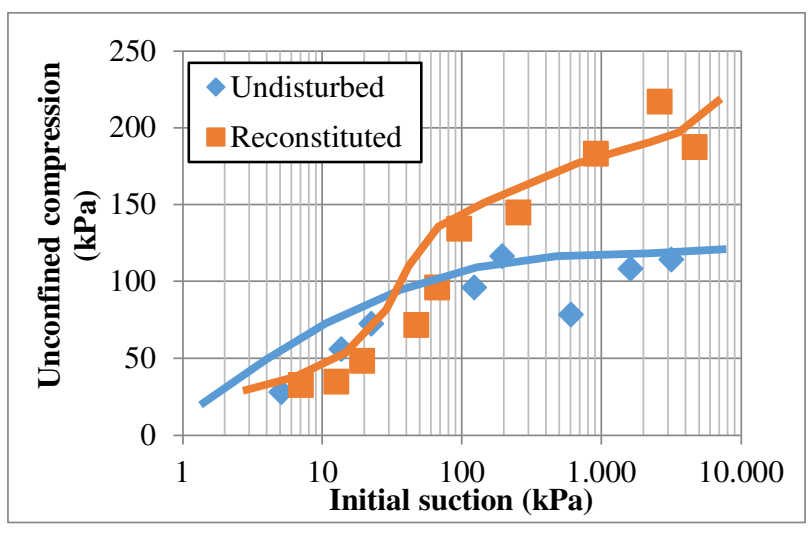

Fig. 12. Friburgo young residual soil. Initial suction vs. unconfined compression strength. 
Contrary to what was observed in the results of the tensile strength of this soil, the resistance to unconfined compression remained stable for suction values higher than the residual moisture value in the undisturbed samples and showed an increase in the reconstituted samples. Fig. 13 shows the failure surfaces of some cylinders of this soil.

As in the diametrical compression test, this soil did not show a great loss of resistance after high suction values, maintaining a progressive increase in the parameter until the residual moisture.

From suction values higher than $200 \mathrm{kPa}$, the unconfined compression strength of the reconstituted samples continued to increase until reaching its highest value related to suction around 2.6 $\mathrm{MPa}$. The resistance of the undisturbed samples remained constant around $110 \mathrm{kPa}$.

According to Motta (2016) [5], this difference may have occurred due to the presence of weaknesses in the structure of the young residual soil caused by its great heterogeneity. On the other hand, the homogeneity of the reconstituted samples provided this higher resistance values, reaching up to $217 \mathrm{kPa}$.

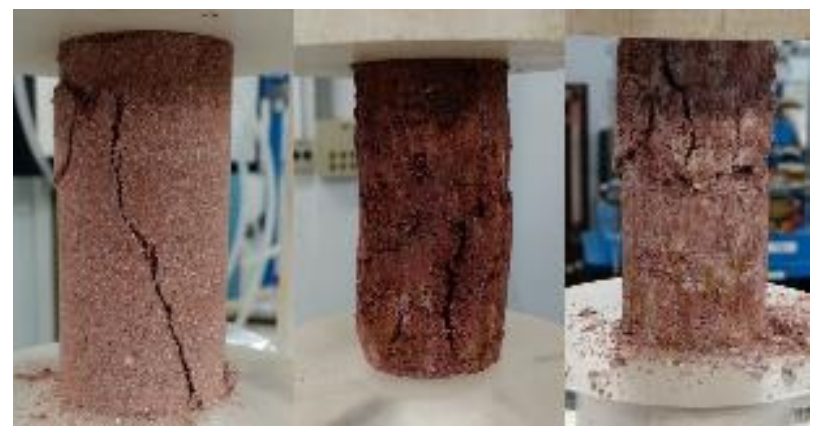

Fig. 13. Friburgo young residual soil. Failure surfaces.

Fig. 14 and 15 present the stress vs. axial strain curves for undisturbed and reconstituted samples, respectively. Similarly to the Tinguá soil, it was observed a brittle behavior, with a resistance loss after the maximum stress value. The elastic modulus was higher for drier samples.

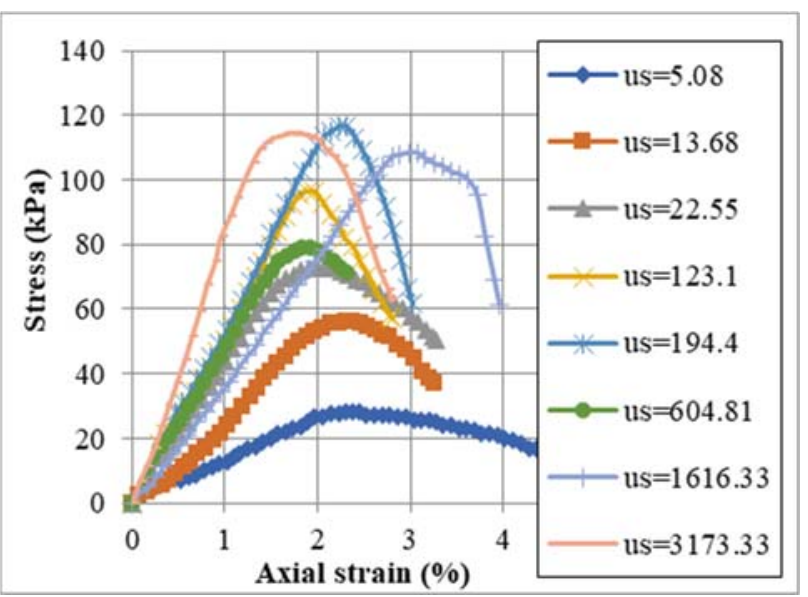

Fig. 14. Friburgo young residual soil undisturbed samples. Stress vs. axial strain. Initial suction $\left(\mathrm{u}_{\mathrm{s}}\right)$ values in $\mathrm{kPa}$.

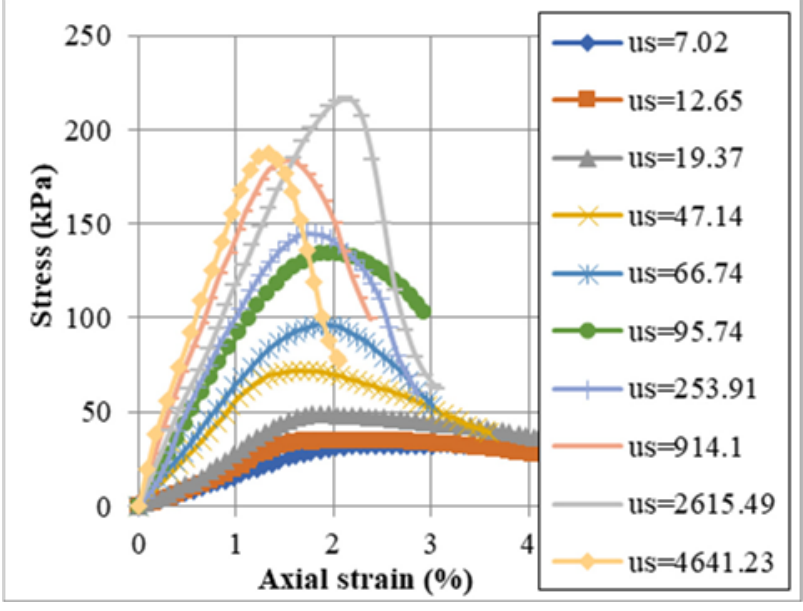

Fig. 15. Friburgo young residual soil reconstituted samples. Stress vs. axial strain. Initial suction $\left(\mathrm{u}_{\mathrm{s}}\right)$ values in $\mathrm{kPa}$.

\subsection{PUC's colluvium}

For this soil, the effect of drying on its mechanical properties was studied without considering the influence of its structure. The tests were performed on undisturbed samples only.

\subsubsection{Soil-water characteristic curve}

The soil-water characteristic curve of this soil showed a bimodal behavior as can be seen in Fig. 16 through the graph of volumetric moisture as a function of suction.

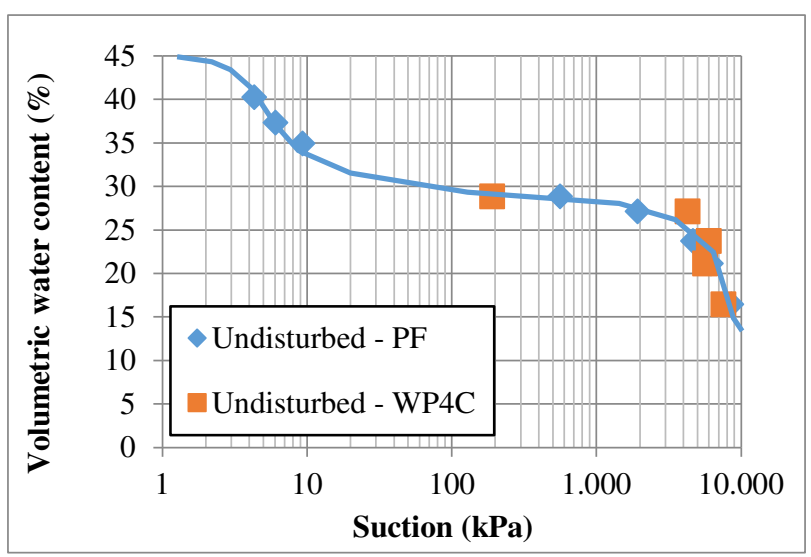

Fig. 16. PUC colluvium. Soil-water characteristic curve.

The first and the second air-entry values and residual moisture can be obtained for the material. The first airentry occurs with a suction of $2 \mathrm{kPa}$, while the first residual moisture around $15 \mathrm{kPa}$. The second ai-entry occurs at $2.7 \mathrm{MPa}$, while the residual final drainage zone of this soil occurs in higher suctions, exceeding $10 \mathrm{MPa}$.

\subsubsection{Tensile strength}

The tensile strength of the colluvium, presented in Fig. 17 as a function of initial suction, showed a gradual increase as it lost moisture, reaching a maximum value of $70 \mathrm{kPa}$, associated with a suction of $2 \mathrm{MPa}$. From this point on, the drying process led to a loss of resistance. 


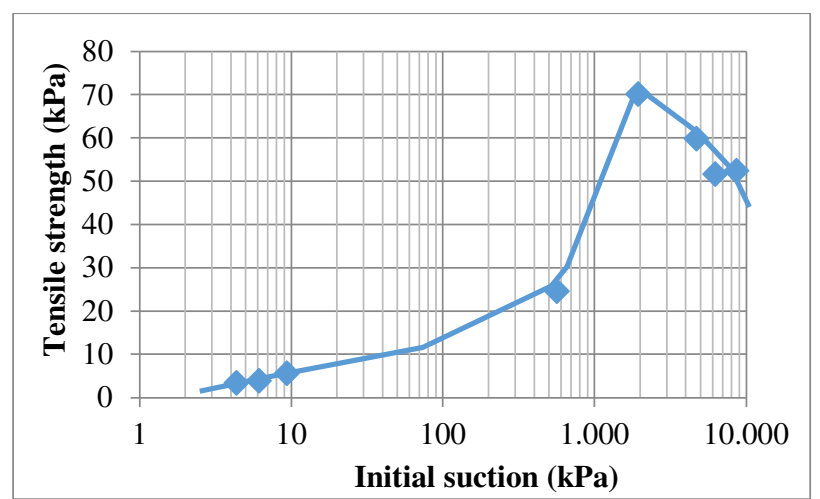

Fig. 17. PUC colluvium. Initial suction vs. tensile strength.

\subsubsection{Unconfined compression strength}

In this test, there was a considerable similarity with the results of diametrical compression as a function of initial suction. Such similarity can be observed when comparing the curve in Fig. 18 with that in Fig. 17.

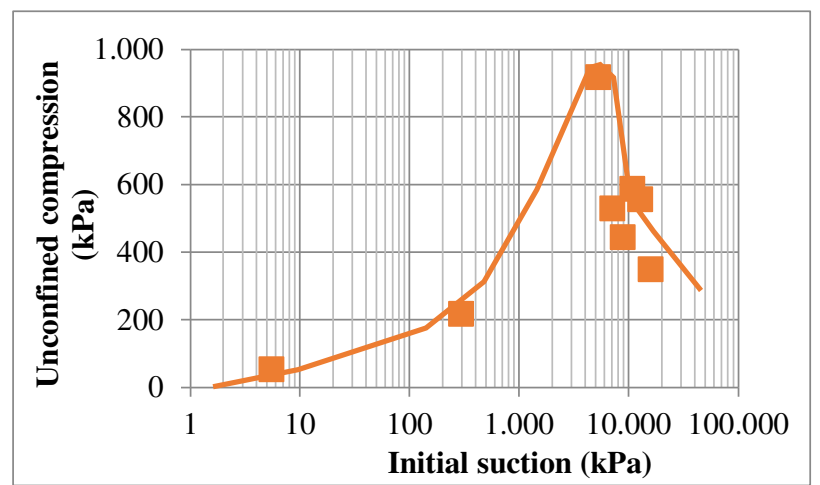

Fig. 18. PUC colluvium. Initial suction vs. unconfined compression strength.

As in the samples submitted to the Brazilian Test, the resistance to uniaxial compression showed a great increase during the drying process, reaching a maximum value of $900 \mathrm{kPa}$ for a suction of 5.2 MPa. After the peak, the decrease in the volume of water in the pores caused a drop in the resistance parameters, reaching $350 \mathrm{kPa}$ when associated with the residual moisture of the material. Fig. 19 shows the failure surface of some of the samples from this soil.

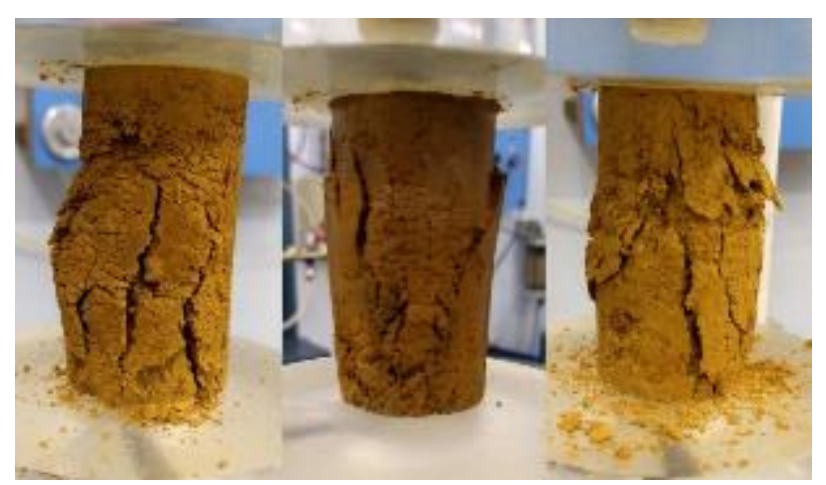

Fig. 19. PUC colluvium. Failure surfaces.
Fig. 20 presents the stress vs. axial strain curves for the PUC colluvium samples submitted to unconfined compression tests with different initial suction $\left(\mathrm{u}_{\mathrm{s}}\right)$ values.

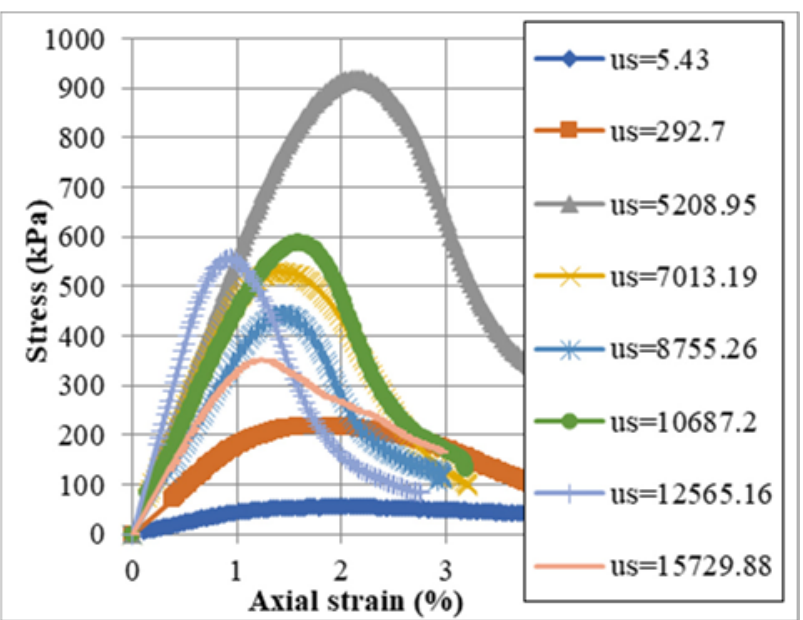

Fig. 20. PUC colluvium. Stress vs. axial strain. Initial suction $\left(\mathrm{u}_{\mathrm{s}}\right)$ values in $\mathrm{kPa}$.

\section{Conclusions and suggestions}

The main objective of this work was to evaluate the influence of increased suction over two soil resistance parameters - tensile strength and unconfined compression strength. For this purpose, tests were carried out to obtain the soil-water characteristic curve of each material studied and the parameters mentioned. It was observed for all soils tested that their resistance gradually increases with the beginning of the soil drying process.

When analyzing the relationship between the increase in suction and the tensile strength, it was noticed that the undisturbed samples of the Tinguá young residual soil and the PUC's colluvium showed a similar behavior, with a sudden loss of resistance after reaching the maximum value. This pattern was also observed when correlating unconfined compression strength and suction for colluvium.

All samples from Friburgo and reconstituted samples from Tinguá presented only resistance gain related to the drying process. For high suction values the resistance has stabilized or maintained growth. This behavior could also be noticed in the unconfined compression tests of the two residual soils studied.

The evolution of the elastic modulus of the samples as a function of suction proved to be like the unconfined compression strength of the respective soils.

Another aspect verified in this work was to carry out the comparison between two methodologies for obtaining soil suction. The combined use of the filter paper technique with the WP4C Dewpoint Potentiometer to obtain the hybrid soil-water characteristic curve presented satisfactory results, with matric and total suction measurements close to each other, especially for values above $500 \mathrm{kPa}$.

The third objective of this work was to verify the influence of the structure of the residual soils, comparing the tensile strength vs. suction and unconfined 
compression strength vs. suction for undisturbed and reconstituted samples.

For the Tinguá young residual soil, it was found that the structure affected only the tensile strength of the soil, since the alignment of the micas generated an increase of resistance in the reconstituted samples. The behavior of the two groups of samples submitted to the uniaxial compression test was similar.

In case of the Friburgo soil, the undisturbed and reconstituted samples showed similar behavior, with resistance gain as the suction increased. However, in the diametrical compression tests, the first group of samples reached higher values of resistance, while in the uniaxial compression tests the second group registered a greater gain of this parameter. The structure influenced this behavior, since weakened surfaces may have decreased the strength of samples submitted to unconfined compression.

As a suggestion for future research, a deeper assessment of the behavior of the mechanical resistance of soils with increased suction is recommended since the drying of the soil would only generate an increase in apparent cohesion. However, a study of the structure of these soils and possible microcracks in it through electronic tomography can be used for this purpose.

In addition, to obtain a more complete soil-water characteristic curve, it is possible to use desiccators, where the samples can equalize with saline solutions with known molality and, therefore, known suction. This method could provide experimental points for stretches where results are lacking.

\section{References}

1. A. T. A. Brito (1981). Estudo químico e mineralógico de um perfil de alteração de gnaisse migmatítico do Campo Experimental da PUC-Rio.

2. R. M. Soares (2005). Resistência ao cisalhamento de um solo coluvionar não saturado do Rio de Janeiro, RJ.

3. F. A. M. Marinho (1994). Medição de sucção com o método do papel filtro. X Congresso Brasileiro de Mecânica dos Solos e Engenharia de Fundações 2, 515-522.

4. R. J. Chandler, M. S. Crilley, and G. MontgomerySmith (1992). A low-cost method of assessing clay dessication for low-rise buildings. Proc. Instn. Civ. Engrs. Civ. Engng, 82-89.

5. M. F. B. Motta (2016). Caracterização físico-hídricoestrutural e efeito do aumento da pressão de ar na resistência de solos tropicais não saturados. 